\title{
ChemComm
}

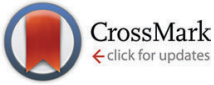

Cite this: Chem. Commun., 2014, 50, 14338

Received 3rd September 2014, Accepted 29th September 2014

DOI: $10.1039 / \mathrm{c} 4 \mathrm{cc} 06964 a$

www.rsc.org/chemcomm

\section{Single-walled carbon nanotubes as nano- electrode and nano-reactor to control the pathways of a redox reaction $\dagger$}

\author{
Robert L. McSweeney, ${ }^{a}$ Thomas W. Chamberlain, ${ }^{\star a}$ E. Stephen Davies ${ }^{a}$ and \\ Andrei N. Khlobystov*ab
}

\begin{abstract}
Single-walled carbon nanotubes have been demonstrated as effective nanoscale containers for a redox active organometallic complex $\mathrm{Cp}^{\mathrm{Me}} \mathrm{Mn}(\mathrm{CO})_{3}$, acting simultaneously as nano-electrode and nanoreactor. Extreme spatial confinement of the redox reaction within the nanotubes changes its pathway compared to bulk solution due to stabilisation of a reactive intermediate.
\end{abstract}

Carbon nanotubes, renowned for their high electrical conductivity, ${ }^{1}$ have found applications in solution-based electrochemistry as nanoscale electrodes with large electrochemically active surfaces and with increased sensitivity for detecting analyte molecules. ${ }^{2,3}$ In addition to their large external surface, single-walled carbon nanotubes (SWNTs) possess internal cylindrical cavities typically 0.9-2.0 $\mathrm{nm}$ in diameter, commensurate with the sizes of small/ medium molecules. Inserted in SWNTs, the guest-molecules have been shown to modify the intrinsic electronic properties of the host-nanotubes thus enabling improved electrochemical sensing for $\mathrm{H}_{2} \mathrm{O}_{2}{ }^{4}$ and dopamine, ${ }^{3,5}$ or facilitating electrochemically tuneable optical properties that can be controlled by adjusting the applied potential. ${ }^{6,7}$ Herein we demonstrate that a carbon nanotube electrode is not only a useful surface for enhancing the detection of redox processes, but the confinement of guestmolecules at the nanoscale can change the pathways of their electrochemical transformations with the nanotube acting simultaneously as a nano-electrode and nano-reactor.

In order to control the reactivity of molecules through nano-scale confinement it is essential that they are securely entrapped in nanotubes. We employ SWNTs with an average diameter of $1.4 \mathrm{~nm}$ to match the size of small organometallic molecules and to provide efficient encapsulation. For example,

\footnotetext{
${ }^{a}$ School of Chemistry, The University of Nottingham, University Park, Nottingham, NG7 2RD, UK. E-mail: thomas.chamberlain@nottingham.ac.uk, andrei.khlobystov@nottingham.ac.uk; Fax: +44 (0)115 9513563; Tel: +44 (o)115 9513917

${ }^{b}$ Nottingham Nanotechnology and Nanoscience Centre, University of Nottingham, University Park, Nottingham, NG7 2RD, UK

$\dagger$ Electronic supplementary information (ESI) available. See DOI: 10.1039/ c4cc06964a
}

metal hexacarbonyls ${ }^{8}$ or metallocenes ${ }^{9-13}$ can be inserted in such nanotubes from gas or liquid (molten) phases forming 1D molecular arrays within the nanotube cavity. In our study we investigate a half-sandwich complex $\mathrm{Cp}^{\mathrm{Me}} \mathrm{Mn}(\mathrm{CO})_{3} 1$ that possesses both, the characteristics of metallocenes (i.e. a $\mathrm{Cp}^{\mathrm{Me}}$ ligand) providing effective interactions with the nanotube $\pi$-system, as well as three carbonyl ligands that can serve as a spectroscopic marker and good leaving groups in electrochemical reactions. The complex is also known to act as a catalyst for important processes such as CO fixation, ${ }^{14}$ disulphide formation ${ }^{15}$ and $\mathrm{H}_{2}$ production, ${ }^{15,16}$ making the hybrid structures in which the complex, $\mathbf{1}$, is encapsulated inside the nanotubes (1@SWNT) suitable for a number of potential applications. Nanotubes were opened by controlled oxidation in air and immediately after being opened were immersed in 1, a liquid at room temperature, allowing encapsulation of the guest-molecules by capillary forces. After excess 1 was removed from the surface of the SWNTs, IR bands at 2023 and $1940 \mathrm{~cm}^{-1}$ observed for 1@SWNT clearly indicated successful insertion of complex 1 from the liquid phase into the nanotube cavity (Fig. 2c). The carbonyl stretching vibrations appear to be slightly blue-shifted (by 2 and $6 \mathrm{~cm}^{-1}$ respectively) as compared to the free complex indicating a small amount of charge transfer from the Mn(I) centre to the nanotube sidewall which is to be expected as the host-SWNTs often behave as effective electron acceptors with respect to encapsulated guestmolecules. ${ }^{8}$ High-resolution transmission electron microscopy (HRTEM), which enables local-probe analysis with near atomic resolution, confirmed that the nanotubes have no surfaceadsorbed molecules of $\mathbf{1}$ and showed dark-contrast features in the internal cavities that correspond to Mn metal clusters (Fig. 2a). The molecules of complex $\mathbf{1}$ appear to be extremely unstable under the electron beam, rapidly losing ligands and decomposing into metallic Mn even at a reduced energy (100 keV) and dose rate $\left(\sim 10^{6} \mathrm{e} \mathrm{nm}^{-2} \mathrm{~s}^{-1}\right)$ on the specimen. Energy dispersive X-ray (EDX) analysis recorded for individual or small bundles of SWNTs using a focused e-beam (diameter 3-5 $\mathrm{nm}$ ) identifies the clusters inside the nanotubes as Mn (Fig. 2b). The fact that Mn is always observed inside the nanotubes confirms the efficient encapsulation 


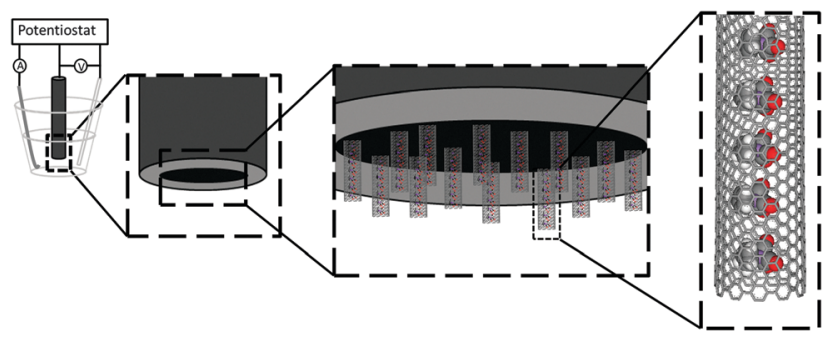

Fig. 1 A three electrode set up is used with a $\mathrm{Ag} / \mathrm{AgCl}$ reference electrode, a platinum counter electrode and SWNTs, deposited on a glassy carbon working electrode, in which the investigated species, $\mathrm{Cp}^{\mathrm{Me}} \mathrm{Mn}(\mathrm{CO})_{3}$, is encapsulated.

a)

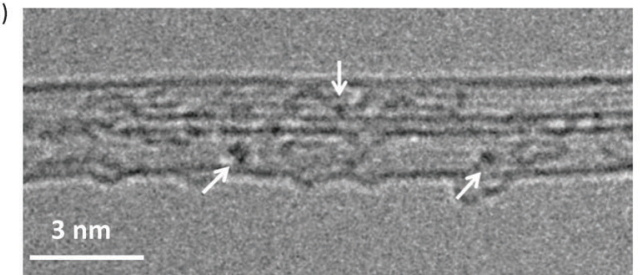

b)
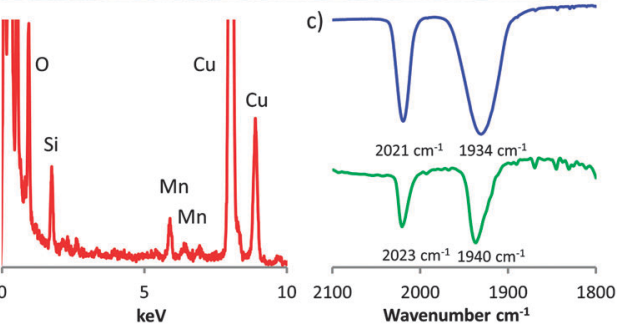

Fig. 2 (a) HRTEM image of two $\mathrm{Cp}^{\mathrm{Me}} \mathrm{Mn}(\mathrm{CO})_{3}$ (SWNT structures showing $\mathrm{Mn}$ metal as dark contrast (white arrows) located solely inside the SWNT. (b) EDX spectra confirming the presence of $\mathrm{Mn}$ in the $\mathrm{Cp}^{\mathrm{Me}} \mathrm{Mn}(\mathrm{CO})_{3}$ (aSWNT sample (Cu peaks are due to the sample holder) (c) infra-red spectroscopy of free $\mathrm{Cp}^{\mathrm{Me}} \mathrm{Mn}(\mathrm{CO})_{3}$ (blue) and $\mathrm{Cp}^{\mathrm{Me}} \mathrm{Mn}(\mathrm{CO})_{3} \mathrm{QSWNT}$ (green) shows a blue shift in $\nu(\mathrm{CO})$ upon nanotube confinement.

of the complex. The occupancy of the internal space within SWNTs channels was determined to be $c a .62 \%$ by a number of independent methods (see ESI $\dagger$ ), which indicates that the majority of hostnanotubes are filled with complex 1, while some remain empty, perhaps due to internal blockages in the extremely narrow internal channels of the SWNTs.

The complex 1 has an oxidation at $0.80 \mathrm{~V}\left(v s . \mathrm{Fc}^{+} / \mathrm{Fc}\right)$ on a glassy carbon electrode (GCE) producing a highly reactive species $\mathbf{1}^{\mathbf{1 +}}$ that undergoes rapid nucleophilic substitution of one of the CO ligands by a molecule of solvent (acetonitrile) (Fig. 3a) leading to the formation of a new complex, $2^{1+}$. The complex $\mathbf{2}^{\mathbf{1 +}}$ then reduces to its neutral form at a significantly lower potential $\left(-0.18 \mathrm{~V}\left(v s . \mathrm{Fc}^{+} / \mathrm{Fc}\right)\right.$; Fig. 3a) than would be expected for $\mathbf{1}^{\mathbf{1 +}}$, so that the observed cyclic voltammogram can be rationalised as a result of an electrochemical reaction, $\mathbf{1} \rightarrow \mathbf{1}^{\mathbf{1}^{+}} \rightarrow \mathbf{2}^{\mathbf{1}^{+}} \rightarrow \mathbf{2}$ (Fig. $3 \mathrm{~b}$ ) which is consistent with previous studies on the nucleophilic substitution of $\mathrm{CO}$ by $\mathrm{CH}_{3} \mathrm{CN}$ in this complex. ${ }^{14,15}$ Attaching empty SWNTs to the GCE electrode surface (ca. $0.14 \mathrm{mg} \mathrm{cm} \mathrm{cm}^{-2}$ ) increases the electrochemically active surface area by a factor of 3.75 , manifested in a significant increase in current in the $\mathrm{CV}$ process (see $\mathrm{ESI} \dagger$ ), however, the a)
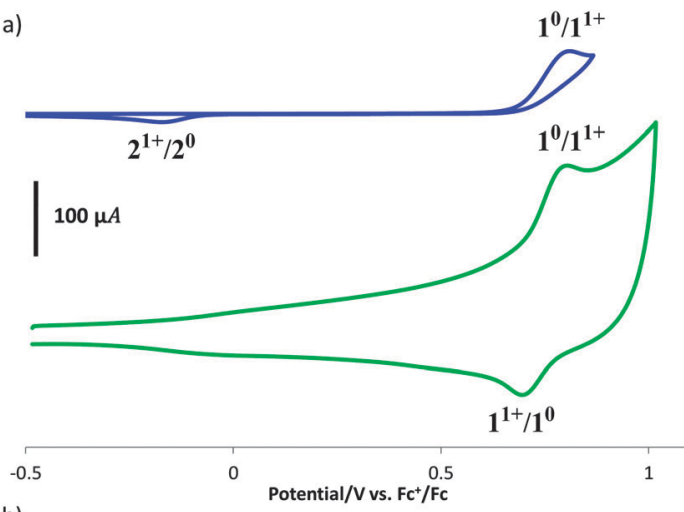

b)

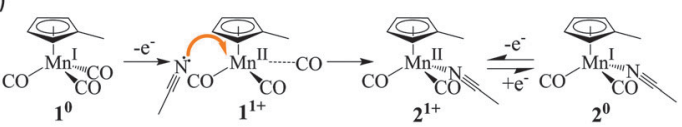

c)

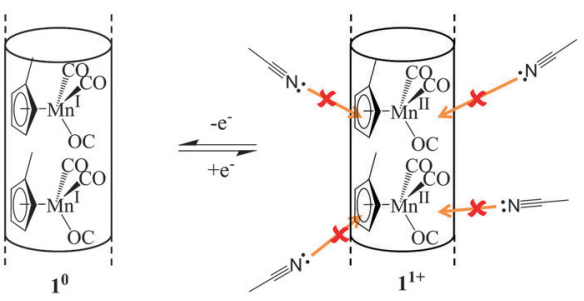

Fig. 3 Cyclic voltammograms of $\mathrm{Cp}^{\mathrm{Me}} \mathrm{Mn}(\mathrm{CO})_{3} \mathrm{ASWNT}$ on GCE (green) showing the chemically reversible oxidation of $1^{0} / 1^{1+}$ and $\mathrm{Cp}^{\mathrm{Me}} \mathrm{Mn}(\mathrm{CO})_{3}$ in solution using a GCE (blue) showing the oxidation of $1^{0} / 1^{1+}$ and subsequent reaction of $1^{1+}$ with MeCN solvent to form $2^{1+}$ followed by reduction to form $\mathbf{2}^{0}$ (b). Nanotube confinement prevents reaction of $1^{1+}$ with the $\mathrm{MeCN}$ solvent such that the reduction of $1^{1+}$ is observed (c). All cyclic voltammetry experiments were performed in $\mathrm{MeCN}$ at $293 \mathrm{~K}$ containing $\left[\mathrm{N}^{n} \mathrm{Bu}_{4}\right]\left[\mathrm{BF}_{4}\right](0.1 \mathrm{M})$ as the supporting electrolyte at a scan rate of $100 \mathrm{mV} \mathrm{s}^{-1}$.

pathway of the reaction remains essentially the same, indicating that the redox processes take place in the solution around nanotubes (i.e. within the diffusion layer) where the molecules are surrounded by acetonitrile which acts as a nucleophile. In contrast, when the complex, $\mathbf{1}$, is inserted in nanotubes (i.e. no longer in solution), and the 1@SWNTs host-guest structures are securely attached to the GCE (Fig. 1), the redox active molecules are in a different environment as compared to bulk solution experiments. In a typical CV experiment the complex, 1, remains inside the nanotubes, which indicates that all of the molecules are electrically connected to the GCE throughout the potential scan via the carbon nanotubes which act as a physical bridge between the individual encapsulated molecules and the macroscopic GCE electrode. It is remarkable that the total amount of $\mathbf{1}$ in the CV experiment with 1@SWNT is estimated to be $\sim 1.3 \mu \mathrm{g}$, which is 838 times less than experiments in which $\mathbf{1}$ is in solution. However in the bulk solution of $\mathbf{1}$ only a small fraction of total number of molecules are in the vicinity of the SWNT surface that is, in the diffusion layer, and thus available to undergo the redox process. Unlike the solution experiments, all of the molecules in 1@SWNT undergo oxidation and reduction in each CV cycle, so that the current associated with these reactions is significantly greater than in the solution CV measurements (Fig. 3a). 
a)

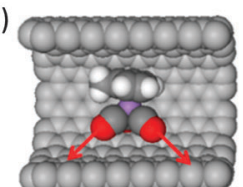

d)
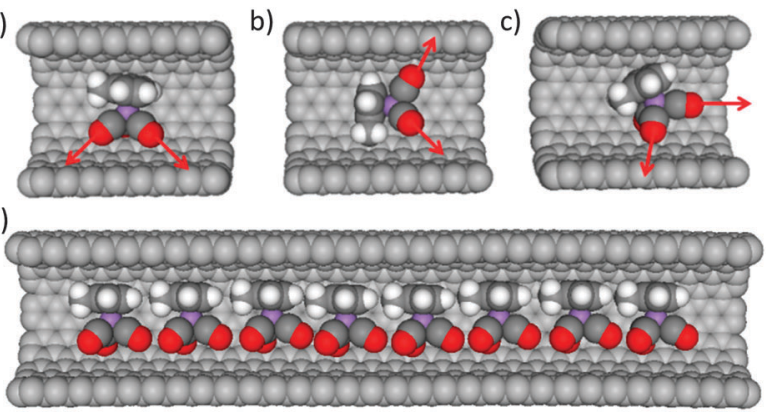

Fig. 4 Molecular diagrams demonstrating that an elimination of $\mathrm{CO}$ cannot occur in (a) and (b) but only in certain orientations of the $\mathrm{Cp}^{\mathrm{Me}} \mathrm{Mn}(\mathrm{CO})_{3}$ inside SWNT, such as (c), due to the nanotube sidewall. If the correct orientation is achieved, there will be another adjacent $\mathrm{Cp}^{\mathrm{Me}} \mathrm{Mn}(\mathrm{CO})_{3}$ molecule providing a further steric barrier to $\mathrm{CO}$ elimination (d). Adjacent $\mathrm{Cp}^{\mathrm{Me}} \mathrm{Mn}(\mathrm{CO})_{3}$ molecules and the nanotube prevent the possibility of a nucleophilic substitution of $\mathrm{CO}$ by $\mathrm{CH}_{3} \mathrm{CN}$

Another significant observation is that the oxidation potential of 1 inside nanotubes becomes more positive by $0.034 \mathrm{~V}$ with respect to free molecules of $\mathbf{1}$ at $-40{ }^{\circ} \mathrm{C}$ in solution $^{14}$ (see ESI $\dagger$ ). The shift in potential correlates well with the IR spectroscopy for 1@SWNT both indicating that the nanotube behaves as a weak electron acceptor. However most importantly, the $\mathrm{CV}$ for 1@SWNT indicates a clear redox process at $0.75 \mathrm{~V}\left(v s . \mathrm{Fc}^{+} / \mathrm{Fc}\right)$ associated with $\mathbf{1} \rightarrow \mathbf{1}^{\mathbf{1 +}} \rightarrow \mathbf{1}$ which is absent for all experiments carried out with $\mathbf{1}$ in solution. It appears that encapsulation of $\mathbf{1}$ in nanotubes changes the pathways of the electrochemical transformations by making the previously irreversible oxidation of $\mathbf{1}$ chemically reversible, which is different to the solution phase where immediately after oxidation $\mathbf{1}^{\mathbf{1 +}}$ irreversibly transforms to $\mathbf{2}^{\mathbf{1 +}}$. In essence, the CV measurements for 1@SWNT demonstrate that the nucleophilic substitution of $\mathrm{CO}$ for $\mathrm{CH}_{3} \mathrm{CN}$ is hindered for reactive intermediate $\mathbf{1}^{\mathbf{1 +}}$ due to the confinement imposed by the nanotube. Considerations of the basic geometry and size of the guest molecules with respect to the nanotube channel suggest that the SWNT sidewall severely limits the mobility of the CO leaving group for most of the orientations of the complex (Fig. 4a-c). Even if dissociation of the Mn-CO bond is successful upon oxidation of $\mathbf{1}$ to $\mathbf{1}^{\mathbf{1 +}}$ and acetonitrile molecules are able to diffuse into the nanotube, the approach of a $\mathrm{CH}_{3} \mathrm{CN}$ nucleophile to the $\mathrm{Mn}$ centre is hindered by the confinement, prohibiting the transition state required for either $S_{N} 1$ or $S_{N} 2$ reaction mechanisms. ${ }^{14}$ Overall, the severe geometrical restrictions in conjunction with a physical barrier to nucleophilic attack imposed by the nanotube preserve the reactive intermediate $\mathbf{1}^{\mathbf{1 +}}$ thus enabling a chemically reversible redox process.

Considering that carbon nanotubes themselves possess remarkable tuneable electrochemical properties, ${ }^{17}$ which can be modified through sidewall functionalisation ${ }^{18,19}$ and effectively integrated with standard electrochemical devices, ${ }^{20,21}$ the use of SWNTs as electrochemical nanoreactors opens up new horizons for analytical and synthetic chemistry.

With their diameters at the nanoscale and nearly macroscopic lengths, carbon nanotubes are excellent structures for connecting the world of molecules with the macroscopic world. We exploit the high electric conductivity of SWNTs to initiate and measure electrochemical transformations of redox active molecules. Nanotube external and internal surfaces significantly increase the active interface with redox molecules, thus improving the sensitivity of the macro-electrode. Most significantly, an electrochemical reaction pathway can be altered by restricting the reaction volume within the nanotube channel, which offers a powerful new tool for controlling electrochemical reactivity at the nanoscale.

This work was supported by the European Research Council (ERC), the Engineering and Physical Sciences Research Council (EPSRC) and the University of Nottingham.

\section{Notes and references}

1 T. W. Ebbesen, H. J. Lezec, H. Hiura, J. W. Bennett, H. F. Ghaemi and T. Thio, Nature, 1996, 382, 54.

2 A. Le Goff, F. Moggia, N. Debou, P. Jegou, V. Artero, M. Fontecave, B. Jousselme and S. Palacin, J. Electroanal. Chem., 2010, 641, 57.

3 S. Sansuk, E. Bitziou, M. B. Joseph, J. A. Covington, M. G. Boutelle, P. R. Unwin and J. V. Macpherson, Anal. Chem., 2013, 85, 163.

4 N. Sun, L. Guan, Z. Shi, N. Li, Z. Gu, Z. Zhu, M. Li and Y. Shao, Anal. Chem., 2006, 78, 1148.

5 H. M. Cheng, H. X. Qiu, Z. W. Zhu, M. X. Li and Z. J. Shi, Electrochim. Acta, 2012, 63, 83.

6 K. Yanagi, R. Moriya, C. Nguyen Thanh, M. Otani and S. Okada, Phys. Rev. Lett., 2013, 110, 086801.

7 L. Kavan, L. Dunsch and H. Kataura, Carbon, 2004, 42, 1011.

8 T. W. Chamberlain, T. Zoberbier, J. Biskupek, A. Botos, U. Kaiser and A. N. Khlobystov, Chem. Sci., 2012, 3, 1919.

9 L. J. Li, A. N. Khlobystov, J. G. Wiltshire, G. A. D. Briggs and R. J. Nicholas, Nat. Mater., 2005, 4, 481.

10 D. E. Luzzi, B. W. Smith, R. Russo, B. C. Satishkumar, F. Stercel and N. Nemes, Am. Inst. Phys., Conf. Proc., 2001, 591, 622.

11 H. Shiozawa, C. E. Giusca, S. R. P. Silva, H. Kataura and T. Pichler, Phys. Status Solidi B, 2008, 245, 1983.

12 M. Sauer, H. Shiozawa, P. Ayala, G. Ruiz-Soria, X. J. Liu, A. Chernov, S. Krause, K. Yanagi, H. Kataura and T. Pichler, Carbon, 2013, 59, 237.

13 H. Shiozawa, T. Pichler, R. Pfeiffer, H. Kuzmany and H. Kataura, Phys. Status Solidi B, 2007, 244, 4102.

14 J. W. Hershberger, R. J. Klingler and J. K. Kochi, J. Am. Chem. Soc., 1983, 105, 61.

15 J. W. Hershberger and J. K. Kochi, J. Chem. Soc., Chem. Commun., 1982, 212.

16 J. W. Kee, Y. Y. Tan, B. H. G. Swennenhuis, A. A. Bengali and W. Y. Fan, Organometallics, 2011, 30, 2154.

17 S. A. Hodge, S. Fogden, C. A. Howard, N. T. Skipper and M. S. P. Shaffer, ACS Nano, 2013, 7, 1769.

18 D. Tasis, N. Tagmatarchis, A. Bianco and M. Prato, Chem. Rev., 2006, 106, 1105.

19 E. L. S. Wong and R. G. Compton, J. Phys. Chem. C, 2008, 112, 8122.

20 R. T. Kachoosangi, M. M. Musameh, I. Abu-Yousef, J. M. Yousef, S. M. Kanan, L. Xiao, S. G. Davies, A. Russell and R. G. Compton, Anal. Chem., 2009, 81, 435.

21 T. S. Miller, J. V. Macpherson and P. R. Unwin, Phys. Chem. Chem. Phys., 2014, 16, 9966. 